\title{
FORMULAÇÃO E IMPLEMENTAÇÃO DE POLÍTICAS COMO PEDAGOGIAS PARA A GESTÃO: UM ENSAIO A PARTIR DE TRÊS CASOS DO SISTEMA ÚNICO DE SAUDE
}

Development and implementation of policies as pedagogies for management: a test case a three from the public health system

\section{Heider Aurélio Pinto}

Mestre em Saúde Coletiva.

Secretário de Gestão do Trabalho e da Educação na Saúde do Ministério da Saúde, Brasil.

E-mail: heider.aurelio.pinto@gmail. com

\section{Alcindo Antonio Ferla}

Doutor em Educação. Professor Adjunto da Escola de Enfermagem da Universidade Federal do Rio Grande do Sul.

E-mail: ferlaalcindo@gmail.com

\section{Resumo}

A análise da etapa de implementação de políticas públicas tem tido destaque recente e permite compreender os processos e resultados alcançados e, mais do que isso, fortalece a ideia de monitoramento e avaliação para seu acompanhamento. $\mathrm{O}$ artigo, no formato ensaístico, analisa a implementação de três políticas na perspectiva da inovação, considerando atributos de descentralização com autonomia local e inovação institucional. Trata-se das Políticas Nacionais de Humanização e Educação Permanente em Saúde e do Programa Nacional de Melhoria do Acesso e da Qualidade da Atenção Básica (PMAQ). Para efeitos da análise, considera-se que as duas primeiras constituíram uma influência prévia para a viabilidade do PMAQ, conforme modelo de análise da ciência política. Entretanto, também é necessário ultrapassar esse modelo para compreender o PMAQ, em que parece ter incidido o que alguns atores denominam de influência das ideias. Descentralização e autonomia local são ideias fortes para o contexto da reforma sanitária e a existência de propostas nacionais com radicalidade no eixo político da implementação dessas ideias também constitui condição para a viabilidade da formação de políticas. O PMAQ parece ter sua formação atravessada por essas ideias. A partir dessa análise, o ensaio aponta alguns desafios para as próximas etapas, incluindo a necessidade de que o processo nacional tenha capacidade de fazer avançar o reconhecimento das 
singularidades locais, que a implementação desse programa constitua crescentemente a participação dos diferentes atores para sua sustentação e aprimoramento e que seja fortalecida a produção de conhecimentos e tecnologias para avançarmos na ampliação do acesso e da qualidade, mas que também se forme um campo discursivo em torno dessas ideias. Trata-se de uma oportunidade de, a partir da iniciativa de uma política nacional, operar um movimento com efeito pedagógico de fortalecer a gestão local e de constituí-la para além da capacidade de utilizar normas e técnicas, como gestão viva e criativa.

Palavras-Chave: Educação Permanente em saúde; atenção básica, humanização, $P M A Q$, análise de políticas.

\section{Abstract}

The implementation analysis of public policies has stepped forward and allows us to understand the processes and results achieved and, more than that, has reinforced the monitoring and evaluation idea to follow-up. The article, in essay format, analyzes the implementation of three policies from the perspective of innovation, considering decentralization attributes with local autonomy and institutional innovation. These are The Humanization of National Policies and Permanent Education in Health and the National Access Improvement Program and Quality of Primary Care (PMAQ). For the purposes of analysis, it is considered that the first two were a prior influence for the viability of PMAQ as analysis model of political science. However, it is also necessary to overcome this model to understand the PMAQ, which seems to have focused on what some authors call influence of ideas. Decentralization and local autonomy are strong ideas to the context of sanitary reform and the existence of national proposals with radicalness in the political axis of the implementation of these ideas are also in condition for the viability of training of policies. The PMAQ seems to have its formation traversed by these ideas. From this analysis, the essay points out some challenges for the next steps, including the need for the national process to have capacity of advancing the recognition of local singularities, and the implementation of this program increasingly constitutes the participation of different stakeholders for their support and upgrading, and has strengthened the production of knowledge and technologies advance in the expansion of access and the quality, but that also form a discursive field around these ideas. This is an opportunity to, at the initiative of a national policy, operate a movement with educational effect of strengthening local management and constitute it beyond capacity to use standards and techniques, as a living and creative management.

Keywords: Continuing Education Health; Primary Health Care; Humanization of Assistance; PMAQ; Policy Analysis.

\section{Introdução}

A análise de políticas públicas considera diferentes dimensões do processo a partir do qual uma questão se torna visível no cotidiano de um território determinado, mobiliza um conjunto de atores e seus interesses, constitui certos consensos em torno de caminhos possíveis no contexto de atores sociais e governamentais e recebe um certo formato, tendo ainda uma etapa de implementação, monitoramento e avaliação. Esse processo, denominado ciclo das políticas públicas, tem recebido, mais contemporaneamente, um destaque para a etapa de implementação, uma vez que, ao 
contrário de abordagens mais funcionalistas que pretendiam um processo quase decorrente da sua formulação, entendese atualmente, que a implementação tem grande autonomia em relação às fases anteriores. ${ }^{1}$ Conforme a bibliografia, é possível, inclusive, que o conteúdo do que é implementado, divirja significativamente do que foi formulado como política, devido ao fato de que os atores e seus interesses retornam à cena novamente nessa etapa, disputando os rumos do processo à medida em que segue o jogo da implementação. ${ }^{1,2}$

Estudos já consolidados como referências para o entendimento da implementação do Sistema Único de Saúde (SUS) como política setorial nos auxiliam na compreensão dos jogos e dos principais atores no ciclo da política nacional de saúde. ${ }^{1,2,3}$

Neste artigo, pretendemos analisar, a partir de três casos de políticas específicas, recentes e voltadas para diferentes aspectos do sistema de saúde brasileiro, o processo de implementação, refletindo sobre a possibilidade de inovação, considerando a capacidade de avançar na tensão centralização-descentralização e na inclusão de atores ou estratégias de implementação que não são frequentes, quando tomadas as iniciativas do Ministério da Saúde para a solução de problemas no cotidiano do SUS. A capacidade de inovação é caracterizada, neste artigo, como a superação de uma certa tendência centralizadora e de reciclagem de conteúdos que pertencem à razão biomédica. ${ }^{i}$ A análise de conteúdos e estratégias de implementação procura evidenciar como são constituídos os atores locais, como eles podem dar ênfase a certos aspectos da política e, sobretudo, constituir

i Madel Luz ${ }^{4}$, analisando as políticas de saúde no Brasil, identifica uma grande coincidência entre conteúdos e formas da razão biomédica e as políticas de saúde, permitindo-lhe construir uma categoria teórica de instituições médicas, para referir-se às organizações governamentais que tomam o discurso da biomedicina para orientar sua formulação. aprendizagens para a gestão. Nesse caso, a implementação de uma política também poderia ter caráter de constituir atores, discursos e modos de fazer a gestão.

O tema da inovação nas políticas públicas tem algumas questões teóricas importantes, uma vez que a literatura da ciência política constata uma certa lógica predominante de reciclagem de soluções para a formação de políticas. Menicucci e Brasil $^{2}$ empreenderam um esforço teórico para construção de uma matriz analítica que permite compreender os processos decisórios de políticas também por influência de ideias, não apenas de atores e interesses, colocando o processo político em análise também "na sua dimensão simbólica e enquanto instrumento de ordem interpretativa." 2:370 Assim, novas ideias que sejam tematizadas em uma esfera pública num "contexto favorável a desequilíbrios institucionais podem se tornar influentes e configurarem uma agenda alternativa capaz de levar a alterações institucionais a partir da mobilização de redes de políticas públicas."2:370 Assim, há uma ênfase no caráter simbólico, considerando a contribuição de ideologias e a visão de mundo dos diferentes atores, assim como um plano de interação dialógica entre elas para constituir condições de inovação.

Com o objetivo de evidenciar diferenças no formato centralizador de algumas políticas nacionais, escolhemos fazer uma breve análise da Política Nacional de Humanização (PNH) e da Política Nacional de Educação Permanente em Saúde (PNEPS). Essas duas políticas nacionais foram escolhidas como exemplos que, objetivando mudanças no modo como se organiza o trabalho em saúde, apostaram em diversas estratégias de interação não só com os gestores estaduais e municipais, mas também com trabalhadores e usuários, enfocando $\mathrm{o}$ processo de trabalho. $\mathrm{O}$ Programa Nacional de Melhoria do Acesso e da Qualidade (PMAQ) é também 
uma política que faz estas apostas, mas $o$ analisaremos adiante em maior profundidade nesse aspecto. Iniciar a análise pelas duas iniciativas anteriores traduz nossa convicção de que elas constituem visibilidade para destacar dimensões ainda pouco visíveis do PMAQ. No contexto da análise de políticas, a influência de políticas anteriores é um eixo de análise frequente, entretanto normalmente tem a potência de explicar certas permanências. Nesse caso, nos parece mais adequado consideralas como pertencentes a um certo modo de visualizar a gestão e a relação entre as diferentes esferas de governo que diferem do padrão existente na gestão federal. A existência de políticas prévias poderia tornar visível um conjunto de ideias que são retomadas. Refletir sobre o PMAQ no contexto dessa matriz analítica e a partir de suas potencialidades compõe uma aposta desse ensaio.

\section{Políticas de Humanização e}

Educação Permanente: avanços conceituais e operacionais para a gestão local

A PNH almeja ser uma política transversal com o objetivo de transformar o cotidiano dos serviços, apostando que gestores, trabalhadores e usuários sejam capazes de transformar realidades e a si próprios. ${ }^{5,6}$ Propõe uma compreensão complexa e robusta da realidade e busca enfrentar os modos hegemônicos de administrar os serviços de saúde e as pessoas, de cuidar da saúde e de organizar os serviços fazendo forte afirmação de princípios e conceitos-ferramentas tais como a cogestão, a clínica ampliada, a defesa dos direitos do usuário, o acolhimento, o fomento das grupalidades, etc. As práticas concretas informadas por estes conceitos seriam desenvolvidas nos serviços com a introdução e funcionamento de diversos dispositivos, tais como: o acolhimento com classificação de risco, o grupo de trabalho de humanização, os colegiados gestores, os contratos de gestão, os sistemas de escuta qualificada para usuários e trabalhadores da saúde, o direito à acompanhante, a equipe transdisciplinar de referência e de apoio matricial, os projetos cogeridos de ambiência, o acolhimento com classificação de riscos, o projeto terapêutico singular, o projeto memória do SUS que dá certo, o apoio institucional, etc. ${ }^{7}$ Os documentos orientadores dessa política destacam aspectos da organização do trabalho, quer seja entre a equipe, quer seja na relação com o usuário e a administração de suas demandas. Não se portam como protocolos, pretendendo prescrever o trabalho que deve ser realizado, mas, ao contrário, buscam colocar o trabalho em análise à luz da afirmação de certos princípios e ideiasforça e da oferta de conceitos-ferramenta. Traçam vetores entre os diferentes serviços e a gestão, mobilizando "fluxos" que pretendem conectar diferentes pontos das redes de atenção.

A política de humanização parte do suposto de que o trabalho em saúde está envolto em situações de grande complexidade, necessitando de graus de autonomia importante dos trabalhadores e fluxos de apoio. O "sistema" não estaria apenas constituído por serviços com características diversas, mas mediado pelo trabalho concreto que se desenvolve no seu interior.

Já a PNEPS se anunciou em sua criação como uma estratégia do SUS para a formação e desenvolvimento dos trabalhadores no contexto do trabalho. ${ }^{8}$ Nela, o gestor federal, entendido com o responsável por orientar esta ação no setor, deveria articular os componentes gestão, atenção e participação popular com o componente educação dos profissionais de saúde, objetivando a qualificação de todas estas práticas. A PNEPS fez forte afirmação 
do conceito de EPS compreendido como um processo educativo que "coloca o cotidiano do trabalho - ou da formação - em saúde em análise, que se permeabiliza pelas relações concretas que operam realidades e que possibilita construir espaços coletivos para a reflexão e avaliação de sentido dos atos produzidos no cotidiano." A EPS envolveria também a "construção de relações e processos que vão do interior das equipes em atuação conjunta, - implicando seus agentes -, às práticas organizacionais, - implicando a instituição e/ou o setor da saúde." 9:161

Resumidamente, a política formal, analisada a partir de sua Portaria de criação, definiu as regras de distribuição de recursos para as ações de educação para a saúde no SUS (um escopo mais amplo que a EPS propriamente dita); o fluxo e processo para que projetos pudessem ser analisados e "acreditados" pelo governo federal, "de acordo com as diretrizes e orientações" da política, e assim poderem contar com o recurso previsto; a constituição de um novo espaço loco-regional, os Polos de Educação Permanente, que tinham a atribuição de identificar as demandas do território, processá-las à luz das diretrizes da política e decidir o que seria submetido à avaliação para acreditação do Governo Federal. ${ }^{8}$

Podemos dizer que a PNEPS, em sua implantação, substituiu um modo mais discricionário e convenial do MS decidir e financiar projetos de educação para a saúde por um que previa: recurso previsto a priori para cada unidade da federação e um rito que estabelecia o modo de governos estaduais, municipais einstituições deensino alcançarem este recurso. Neste rito a PNEPS buscou ampliar os atores que participavam até então destas decisões quando definiu que o Polo de EPS seria o novo local formal para estas negociações e decisões e quando apontou sua composição propondo atores - dentre eles as representações de trabalhadores, usuários, educadores e estudantes - cujo fortalecimento dos interesses e perspectiva seriam estratégicos para a mudança almejada pela política.

A política, nesse caso, recoloca a dimensão do trabalho em evidência, considerando-a, na sua constituição complexa, como potencialidade para a aprendizagem. A Educação Permanente em Saúde, conceito-chave da política, é também um modo de organizar as aprendizagens. ${ }^{10}$ Assim, 0 trabalho adquire uma textura que envolve atenção, gestão, ensino e participação, conforme a conhecida figura-metáfora do "quadrilátero da formação". ${ }^{10}$ O desenvolvimento do trabalho é proposto como aprendizagem no cotidiano do trabalho, a partir de questões que emergem no mesmo, constituindo-se como "aprendizagem significativa". ${ }^{10}$ Se os problemas do cotidiano do trabalho são de natureza complexa, não há que prescrever soluções; elas precisam ser engendradas localmente, com aportes do conhecimento sistematizado, com os saberes disponíveis no entorno, com redes de apoio e com a participação possível. Não é uma idealização romântica que retira dos diferentes atores seus distintos interesses, mas uma aposta na cogestão do trabalho e na capacidade local de negociação. $O$ desenvolvimento do trabalho, assim compreendido, constituise numa "travessia de fronteiras"10, já que desloca o limite da possibilidade de sua realização para o campo do "trabalho vivo em ato". ${ }^{12}$

O conteúdo da mudança de ambas as políticas está menos no "o que fazer" e mais no "como fazer" e "para que fazer". Propõem modos contra hegemônicos de fazer coisas que os sujeitos já fazem: as práticas de atenção, gestão, educação e participação. Assim, ganha lugar destacado nas duas a promoção da reflexão crítica e interrogação do sentido do trabalho, a promoção de subjetivações inovadoras e a oferta de conceitos-ferramenta que buscam abrir as práticas dos sujeitos, suas relações e os próprio sujeitos à ação instituinte. ${ }^{13}$ Um ação instituinte para a qual se almeja 
algumas direções uma vez que, seja nos conceitos ofertados, nos dispositivos propostos ou em resultados esperados, ambas as políticas propõem alguns modos de olhar, refletir e agir e algumas coisas a se conquistar e não outras dentre as várias possíveis.

A interação de ambas as políticas não se resume aos gestores do SUS, nem aos atores dos Polos de Educação Permanente, nominados como estrutura de articulação local dos distintos sujeitos que gerem as iniciativas locorregionais, ou aos grupos de trabalho de humanização. Buscam estender aos agentes das práticas nos locais - gerentes de serviços, trabalhadores, usuários, educandos e educadores - almejando envolvê-los para a importância e sentido da mudança. Para promover essa mobilização e assunção de agenda, a PNEPS contava com o apoio dos novos financiamentos, rito e espaços regionais propostos por ela, mas o âmbito mais local, onde de fato se pretendia mudar as práticas, poderia sofrer pouca ou nenhuma influência do decidido no Polo de Educação Permanente se os sujeitos que lá estavam não atuassem especificamente no âmbito dos serviços e dos coletivos de gestão. Assim, tanto a PNEPS como a PNH apostam suas fichas nos diversos modos de mobilização, afecção e produção de redes de reconhecimento, apoio e intervenção entre os atores. Soma nesta linha os processos de mobilização-formação, os espaços virtuais de interação, os eventos de reconhecimento e fortalecimento dos coletivos, modos de divulgação e reflexão de experiências, etc. Precisamente, por tentar mudar práticas para alguns sentidos e modos desejáveis e por buscar interagir também com os agentes das práticas, as duas políticas se ocuparam muito com a disputa simbólica e tecnológica. A ideia-força da integralidade opera fortemente em ambas, entendida não como modelo ideal, mas como dispositivo do âmbito das práticas comprometidas com novos padrões de qualidade da saúde.
É importante destacar também que as duas políticas apostam muito nos dispositivos do apoio institucional e matricial: seja um apoiador do Ministério da Saúde (MS) atuando junto a coletivos das secretarias estaduais ou municipais, em ambos os casos; seja atuando junto ao processo de produção e decisão dos Polos, no caso da PNEPS; junto a equipes de trabalhadores e gerentes em alguns serviços priorizados, no caso da $\mathrm{PNH}$; seja em ambas propondo que os gestores dos outros níveis implantem também seus próprios apoios inovando no modo de fazer gestão, cuidado e educação.

Muito ainda poderia ser discutido sobre estas políticas, mas nossa intenção neste ensaio não é empreender uma análise geral das mesmas e sim identificar nelas modos de formulação de políticas nacionais que escapam de um certo modo fortemente vigente de formular políticas centrado numa hierarquia piramidal (gestão federal - gestão estadual - gestão municipal - gestão local gestão do serviço - equipe no cotidiano do trabalho), e ambas ousaram. E teriam que ousar, pois uma modelagem mais tradicional - centralizada, piramidal, focada na introdução e atualização de procedimentos e conhecimentos ao processo de trabalho -, bem comum em nossas políticas de saúde, não daria conta dos objetivos e características dos problemas e desafios que essas duas políticas buscaram enfrentar. Essa fuga do hegemônico não ocorre sem dificuldades. Seja por não contar com "tradição" numa organização, no caso o MS, que não está a princípio preparada para sua execução (recursos especiais, desenho da organização, características do pessoal, etc.) seja por ter dificuldades de legitimação e reconhecimento na cadeia de decisões. Ambas as políticas, por exemplo, apresentaram dificuldades de serem monitoradas e avaliadas, de maneira mais global e permanente, tanto em termos de implantação quanto em relação aos seus 
avanços e resultados, seja por ter muitos objetivos cuja mudança só se evidencia na micropolítica dos serviços, seja por não serem facilmente "enquadráveis" nos modos instituídos e tradicionais de informação e avaliação ou por não ter instituído estratégias mais específicas e sistemáticas de monitoramento e avaliação.

A nosso ver é fundamental que se promovam, pari passo, mudanças na organização da máquina governamental para que ela tenha melhores condições de desenvolver também políticas com estas características. Sem mecanismo importantes à sua execução (como planejamento e desenvolvimento de pessoal, monitoramento e avaliação, capacidade de operação descentralizada, etc.) a máquina em seu formato tradicional pode condicionar seu desenvolvimento.

Outra questão importante é que políticas que tratam dos modos de fazer e sentidos micropolíticos das ações, necessariamente precisam estar articuladas às políticas que estruturam e organizam as redes de serviços, que buscam induzir o modelo de atenção, que induzem e apontam prioridades para a ação nos serviços. Em termos de financiamento, por exemplo, dez anos de PNEPS e PNH envolveram a execução de menos recursos do que dois meses do financiamento da média e alta complexidade. São as políticas nacionais de atenção básica, de atenção especializada, de urgências, de saúde mental e etc. que reúnem a maior quantidade de recursos financeiros e dispõem de outros tantos meios de mobilização dos gestores municipais, agentes econômicos e também dos trabalhadores na tentativa de capturar, induzir, estimular ou apoiar que ajam de um certo modo. Assim, políticas como a PNH e PNEPS precisam "transversalizar" estas outras, todas se transformando no processo e ampliando exponencialmente a potência de suas ações combinadas. E essa é uma imagem que a própria PNH constrói para si e objetiva não só para o nível federal. ${ }^{6}$

Entendemos que O PMAQ foi beneficiado por ter sido uma política construída após estas duas e ter bebido nesta fonte e nascido num momento em que se buscou construir transversalidades no MS. Discutiremos isso na próxima seção.

\section{O PMAQ como política, como encontro de políticas e como oportunizador de agires}

O PMAQ, tal como a PNH e a PNEPS, é uma política nacional que, para avançar em alguns de seus objetivos, busca produzir mudanças no cotidiano do trabalho em saúde, mobilizando sua dimensão micropolitica e apostando em diversas interações com gestores locais e de serviços, trabalhadores, usuários, instituições de formação, instâncias do controle social e de controle externo e até meios de comunicação.

O PMAQ foi criado em 2011 como a principal estratégia de produção de mudanças nas práticas de gestão, atenção, educação e participação da Política Nacional de Atenção Básica (PNAB), num contexto de fortalecimento da $A B$, de criação das Redes de Atenção à Saúde, de instituição do Programa de Avaliação para a Qualificação do SUS e de normatização de mudanças nos modos de contratualização, planejamento e financiamento do SUS. ${ }^{14}$

Nasceu com a tarefa de ser uma estratégia que, em si e na articulação com diversas outras, enfrentasse condicionantes do desenvolvimento da $A B$ brasileira identificados em espaços tripartites e de controle social do SUS. ${ }^{14}$ Para isso o PMAQ se encontrou com diversas outras políticas e programas: hora incorporou/ressignificou instrumentos e reforçou estratégias, modos de fazer e dispositivos das mesmas (como a autoavaliação da política de avaliação e monitoramentoda $A B$, oscontratos degestão, apoio institucional e acolhimento da $\mathrm{PNH}$, 
a certificação da política contratualização dos hospitais, os planos de EPS da PNEPS, o fortalecimento da participação dos usuários do ParticipaSUS, etc.); hora induziu e fortaleceu ações e buscou resultados dessas políticas (como das políticas de urgência, de saúde mental, de doenças transmissíveis, da Rede Cegonha, etc.); hora se propôs a levantar informações, avaliar e acompanhar produtos para elas (como o censo de UBS para o Requalifica UBS, as práticas da Política Nacional de Práticas Integrativas e Complementares, implantação e uso dos pontos do Telessaúde, etc.). ${ }^{15}$

Com isso, uma primeira reflexão necessária é que, a depender do elemento que se escolha analisar, o PMAQ deve necessariamente ser estudado em conjunto com outras políticas e programas com os quais ele se articula. Como mostramos em trabalho anterior, ${ }^{15}$ ele expressa em seus instrumentos a síntese no contexto nacional do que era prioritário que acontecesse na $A B$, estivesse previsto nele mesmo, na PNAB ou em outras políticas de várias áreas do MS. Ele também avalia resultados para os quais não propõe diretamente outras ações de indução além da própria avaliação, precisamente porque as mais importantes ações de indução e as de investimento, custeio e orientação de implantação estão previstas em outras políticas. Assim, se de um lado é papel também do PMAQ construir um diagnóstico mais amplo que sua intervenção, justamente para orientar a intervenção de outras políticas permitindo aos formuladores nacionais realizar correções de trajetórias, de outro, o Programa não pode ser confundido com toda a política de $A B$ ou como o modo de implantar tudo aquilo que ele avalia e tenta provocar.

O PMAQ, por exemplo, avalia e induz mudanças na estrutura das UBS, mas o programa que financia e dirige essas ações é o "Requalifica UBS"; valoriza e acompanha mudanças nos vínculos de trabalho e nos modos de qualificação da gestão do trabalho, mas são os Protocolos da Mesa de Negociação, o InovaSUS, a Política de Carreiras para o SUS, os indicadores do Contrato Organizativo de Ação Pública que atuam nessa direção; propõe a implantação de diversos dispositivos que devem ser analisados em conjunto com as Políticas das Redes e a PNH, outras com a PNEPS e outras ações de participação junto com o ParticipaSUS, e assim poderíamos multiplicar os exemplos.

O Programa mostrou possuir grande poder de mobilização dos gestores municipais $^{16}$ até pelo importante papel que cumpre na mudança qualitativa $e$ quantitativa do financiamento federal da $A B .{ }^{15}$ Mas, além disso, seja baseando em questionários do MS respondidos por gestores responsáveis pelo programa nos municípios e trabalhadores de equipes participantes, seja reunindo um conjunto de evidências identificadas na própria avaliação do programa, o PMAQ mostrou ter potência também na mobilização de equipes da atenção, da gestão dos serviços e da gestão municipal. ${ }^{15}$

$E$, de fato, esta é uma aposta central do programa: a produção de movimento dos atores locais e o desenvolvimento de uma "dinâmica de atuação, negociação e gestão" que impulsionaria a ação local "permanentemente para a mudança buscando induzir a atuação de um coletivo que, mobilizado pela participação no programa, tenha capacidade de gerir a mudança e de mantê-la sempre ativa e com novos desafios e tarefas." ${ }^{\prime 16}$ Vale destacar que a mudança almejada combina transformações no "o que fazer", no "como fazer", no "pra quê fazer" e "nas condições nas quais se faz".

Para que entendamos como 0 programa busca produzir esse movimento de mudança é fundamental estar atento a alguns aspectos. Um primeiro é que, nacionalmente, O PMAQ busca dinamizar 
um ciclo composto por quatro fases que se inter-relacionam. ${ }^{14}$ Nacionalmente, as que chamam mais atenção são as de adesão e de avaliação externa e certificação, talvez por acontecerem no mesmo período e usarem os mesmos instrumentos em todo o país, por demandarem muita comunicação institucional do MS com todos participantes e por serem as mais marcantes no rito do financiamento do PMAQ. Por tudo que debatemos neste ensaio, sabemos o poder de captura-mobilização que estas fases têm nos olhares dos atores que estão em ação e até dos que analisam esta ação. Podemos dizer que é a face mais visível e identificável do programa.

Contudo, a fase mais importante do PMAQ é a de Desenvolvimento, ${ }^{14}$ na qual os sujeitos locais analisariam a realidade, negociariam e pactuariam prioridades e objetivos para a ação de mudança e promoveriam a mudança das práticas de atenção, gestão, educação e participação. Falamos de um território no qual são necessárias mudanças dos modos de gerir e organizar não só os serviços mas o processo de trabalho em saúde, no campo da micropolítica do trabalho em saúde, das tensões, possibilidades e dificuldades das relações que aqueles coletivos organizados para a produção constroem. São processos eminentemente locais disparados, desenhados e geridos no âmbito da atuação de equipes de atenção e gestão nos serviços, com maior ou menor participação e influência de gestores distritais ou do município. Não é a toa que aqui o PMAQ se assemelha muito na proposição e indução das ações à PNH e PNEPS compartilhando não só dispositivos, mas fortalecendo ações, princípios, conceitos-ferramenta e buscando também alguns resultados em conjunto com essas políticas.

Para facilitar uma discussão que poderia ser longa ofertaremos um mosaico que tenta ilustrar a característica rizomática ${ }^{17}$ do modo como o PMAQ busca oportunizar movimentações e interações dos atores do território.

Podemos imaginar que nos diversos municípios que aderiram, o PMAQ pode: ter dado ao coordenador de $A B$ argumento e a oportunidade de colocar a $A B$ como prioridade da secretaria e da prefeitura, seja pela possibilidade do maior aporte de recursos ou pela maior presença da $A B$ no diálogo, direto ou indireto, com a secretaria de estado e o MS; ter sido pautado pela imprensa, pelo Ministério Público ou pelos sindicatos; ter dado um empurrão para ampliar a equipe de gestão e quiçá, instituir apoio institucional e gerência em algumas UBS; ter ajudado a equipe de gestão a construir o norte de um necessário projeto municipal de desenvolvimento da $A B$ composto por estratégias que produzem maior ou menor singularização e reinvenção do programa; ter significado para a equipe no serviço oportunidades de negociar e conseguir melhores condições de trabalho, instituir fórum regular de negociação e gestão, incremento nos equipamentos e medicamentos disponíveis, a realização de medidas há algum tempo demandadas, mas não priorizadas; ter fortalecido discursos ou ações de sujeitos que antes contavam com pouca referência, norte ou suporte; ter representado para equipes de atenção mais reconhecimento e valorização (pecuniária ou não) para o que é feito; ter intensificado a comunicação e encontros (presenciais e virtuais) com outras equipes e a proximidade com a gestão estimulando a crítica sobre o feito e trocas e reflexões sobre como poderia ser; ter representado para a associação de moradores, provocada pelo conselho municipal, a oportunidade de ir à UBS, tendo ou não conselho local, e pleitear que algumas demandas sejam incluídas no plano de ação do programa; ter chamado a atenção dos usuários que passaram a cobrar na UBS hora marcada para atendimento, escuta qualificada, marcação e recebimento de exames na mesma e 
direito a vinculação de uma maternidade e serviços de referencia; ter provocado ou facilitado algumas destas situações ou diversas outras possíveis.

O fundamental do mosaico é compreender que esses agires singulares e com possibilidades de diversas combinações são justamente o que a articulação entre as fases do programa e um amplo leque de ações do mesmo tenta oportunizar e fortalecer. ${ }^{14,16}$ Mas sem incorrer no erro de supor a realidade mais simples do que realmente é e roteirizar ações que "induziriam" cada uma dessas coisas. Em alguns casos o pessoal da gestão buscará ser o disparador, em outros profissionais podem agir e produzir mudanças, porque muitas coisas estão em seu espaço de governabilidade, até mesmo com pouco apoio da gestão e importante e crescente cobrança dos usuários, por exemplo.

A proposta de ação social do programa reconhece que há um território vivo com atores com graus importantes de autonomia no qual instrumentos, ações, proposições e conceitos de diferentes políticas nacionais, estaduais, municipais e dos próprios serviços perdem suas filiações e se misturam podendo simplesmente serem ignoradas por estes atores ou compor uma reinvenção feita por eles que resulta em alguma mudança de seus agires. Está claro que o programa não se realiza sem a ação dos atores locais ${ }^{16}$ e é justamente por isso que ele pressupõe e aposta na ação dos atores motivados pela realização de interesses e projetos, pela possibilidade de avanços e ganhos concretos ainda que de diversas naturezas e com variadas perspectivas. Daí a busca da contaminação dos grupos e da produção de subjetivações favoráveis à qualificação do processo de trabalho.

Por tudo isso entendemos que, necessariamente, as análises sobre o PMAQ precisam superar o erro de isolá-lo das demais políticas em curso e, por outro lado, de aprisioná-lo das suas dimensões mais visíveis: a avaliação e a certificação. Esses limitadores analíticos teriam como efeito inevitável, multiplicar insuficiências do PMAQ.

Vale observar que as dimensões mais visíveis, agregadas, regulares, uniformes e normalizadas do PMAQ tem capturado não só o foco de algumas análise acadêmicas, mas também a ação das gestões municipais, estaduais e federal em diversas circunstâncias. Ante a possibilidade de adaptar, singularizar e reinventar as ações do programa - ainda que alguns de seus ritos, instrumentos e processos sejam os mesmos em todo o país - muitas equipes de gestão tem apenas buscado implantar burocraticamente a maioria de seus instrumentos e ações.

A nosso ver a ação do próprio Departamento de Atenção Básica (DAB) tem ficado excessivamente mobilizada pela operacionalização de etapas como a adesão, monitoramento de indicadores, ofertas de instrumento para auto-avaliação, avaliação externa, certificação das equipes e o repasse do incentivo financeiro. Diversas ações debatidas neste ensaio e importantes para promover a ação da gestão municipal e local, para provocar a mobilização dos demais atores do território e que ocupou a maior parte da ação governamental federal no caso da PNH e PNEPS tem ocupado pouco o MS. Não se pode dizer, por exemplo, que o modo de agir das referências descentralizadas do MS esteja pautado também com esses objetivos. Talvez porque o modus operandi do MS seja o de ofertar orientações sobre suas políticas e aquilo que ele oferece ou normatiza, mas, mesmo quando consegue relacionar a oferta com a demanda específica, talvez faça menos que o necessário para o fortalecimento do nível local no sentido de que crie, implante e faça a gestão de políticas próprias que adequem e reivente as ofertas nacionais à sua realidade e necessidade.

A importante relação do PMAQ com 
a PNEPS, por exemplo, ainda não têm resultado em ações de EPS estimuladas pelo MS que busquem sinergia com o PMAQ nem que tenham ao menos buscado aproveitar as oportunidades abertas por ele. Um caso bem ilustrativo disso é que, até há bem pouco tempo, os processos de educação do Projeto Mais Médicos para o Brasil, embora dirigido a profissionais que atuam na $A B$ e cujas equipes em sua maioria participam do PMAQ, não buscavam sinergia e nem sequer tematizavam ações e dispositivos propostos pelo $\mathrm{PMAQ}$, era como se ele não existisse.

Para nós isso mostra as dificuldades concretas do MS de operacionalizar uma proposta inovadora que, tendo aproveitado um contexto oportuno, conseguiu na formulação combinar: ações e instrumentos de programas vigentes, com os aprendizados da formulação, implantação e avaliação de políticas ousadas como a PNH e PNEPS, com a normatividade vigente e os modos mais institucionalmente aceitos de financiamento e monitoramento. Dificuldades que se expressam na acomodação da ação do MS naquilo que ele tradicionalmente faz com mais facilidade, sem precisar produzir real transversalidade entre as políticas ou ação singular nos territórios. Porém, é preciso considerar que essa é uma iniciativa recente e que produz estranhamentos no institucionalizado em vários âmbitos, inclusive no Ministério da Saúde. A fase inicial de implementação dá visibilidade às contradições, mas também dá visibilidade às quebras. Uma arena mais ampliada, envolvendo os atores governamentais e a sociedade civil, em particular um enorme conjunto de universidades e de estudos, por certo terá influência no seguimento da sua implementação. Há um marcador relevante em relação a essa potencialidade, que é o surgimento do debate sobre o PMAQ na mídia e nos veículos de divulgação científica. Mas há que se avançar e a análise contextual da iniciativa aponta caminhos.

\section{Apontamentos sobre aprendizagens da gestão para o caminho da implementação do PMAQ}

A perspectiva de análise do PMAQ atravessado por questões das políticas de Humanização e Educação Permanente nos permitem fazer quatro últimos apontamentos que julgamos importantes para considerar nos próximos passos do programa. O primeiro se refere à importância do PMAQ de operacionalizar o que anunciou desde sua formulação: um caminhar progressivo para o reconhecimento e apoio à singularidade dos locais. Para nós é importante um duplo e combinado movimento. De um lado, possibilitar que municípios e mesmo equipes possam recortar os instrumentos e priorizar temas e problemas conforme suas necessidades, potencialidades e interesses. Permitir e, mais do que isso, estimular mais fortemente que os municípios possam, como alguns já fazem, reinventar o programa no âmbito municipal e local, combinando com suas políticas de desenvolvimento do sistema local e, particularmente, da atenção básica. De outro lado, constituir e comunicar melhor um foco nacional para a intervenção estratégica do programa. Diferenciar o foco da ação do foco do olhar de avaliação e diagnóstico. A mistura entre esses dois focos hoje faz com que o programa se caracterize por uma excessiva dispersão de resultados esperados. Com foco nacional mais enxuto haveria mais espaço para recortes específicos dos locais. Poderia constituir um dispositivo de Educação Permanente para a gestão local, não apenas municipal, como também locorregional. Um percurso com destaque para essas questões pode fortalecer o efeito da formação do programa que pode ser compreendida por meio do contexto criado pelas políticas de Humanização e Educação Permanente em Saúde, mas também pela potência política de um conjunto de ideias que são fortes no 
PMAQ.

O segundo se refere às participações dos diferentes atores do cotidiano no Programa. A participação de gestores, trabalhadores e usuários é afirmada como essencial pelo próprio Programa, em especial nas fases de contratualização e desenvolvimento. ${ }^{14}$ Contudo, ofertar ações que provoquem e apoiem os territórios para que isso ocorra é uma das dimensões que ainda não foram adequadamente operacionalizadas pelo MS. Aqui a questão é fomentar a emergência de comunidades epistêmicas e movimentos políticos para a sustentação do caráter inovador da mesma.

Com relação aos usuários organizados, por exemplo, as normas do programa recomendam que a adesão/ contratualização e a apresentação dos resultados das avaliações sejam discutidas com o conselho de saúde do município em questão. O PMAQ oferta aos conselhos acesso virtual aos resultados da avaliação e ainda estimula que sejam implantadas ações de fortalecimento do controle social e da participação da comunidade na gestão dos serviços, valorizando esses elementos nas avaliações e certificação do Programa. Mas essas ações, todas oportunas e necessárias, têm tido muita dificuldade de se traduzir em participação concreta. Ainda que em alguns municípios o PMAQ esteja presente nos debates do conselho municipal de saúde e sua ação seja fortalecida pela atuação de conselhos locais que ele mesmo ajuda a consolidar, podemos dizer que na maioria das cidades não é isso que ocorre. É necessário um esforço nacional que envolva, por exemplo: articulação política com as instâncias organizadas do controle social compondo objetivos comuns e plano de ações compartilhadas; a transversalização desse "comum" em políticas como o ParticipaSUS e na agenda do Conselho Nacional de Saúde, Fórum de Conselhos de Saúde e de várias áreas do MS; o desenvolvimento de uma ação mais próxima dos territórios e com maior presença nos campos simbólicos e micropolíticos, a exemplo do que discutimos ao longo do ensaio; forte investimento em comunicação social para alcançar esse púbico; além, é claro, da possibilidade de todos os atores poderem dar também sua cara ao programa, como foi dito acima. Fazer rodar o vértice da participação, como na metáfora da Educação Permanente em Saúde, pode fortalecer a gestão local no sentido de ampliar a capacidade de organizar processos mais resolutivos e compatíveis com a realidade do trabalho.

O terceiro está relacionado com a necessidade de um esforço massivo para mobilizar e fortalecer atores multiplicadores e ativadores do movimento de mudança. Assim além de iniciativas como a formação de apoiadores e comunidades de práticas, é central um investimento em comunicação - moderno, criativo multimídias e reconhecedor e divulgador das experiências -, combinado com gestão do conhecimento acerca do que têm se aprendido com as experiências e investimento em estratégias de formação de rede horizontais de cooperação e apoio: entre trabalhadores, entre municípios, entre instituições de ensino, etc. Afinal, o conhecimento significativo dos processos de Educação Permanente também é sistematizável e compartilhável. $\mathrm{O}$ envolvimento direto de universidades de grande porte, responsáveis pela formação de parte considerável dos trabalhadores mas, sobretudo, de grande parte do conhecimento que circula e atravessa a formação superior, parece uma aposta adequada e, sobretudo, uma oportunidade de avançar na qualificação das tecnologias de gestão para a saúde.

O último se refere à importância do PMAQ buscar maximizar o seu potencial de comunicação de objetivos, pactos, andamento das ações e resultados. Isso passa por utilizar massivamente a tecnologia de informação para que 
gestores nos diversos níveis, universidades e pesquisadores, equipes da gestão e da atenção, controle social e controle externo, imprensa e cidadãos em geral tenham acesso às informações ainda que com perfis de acesso adequados aos interesses e usos que cada um desses atores possa fazer da mesma. Por exemplo, parte da atitude de não reconhecimento de si no programa que as equipes de atenção apresentam hoje passa por não conseguirem dar sua cara ao programa (como já reforçamos diversas vezes), não perceberem os pares envolvidos nem contarem com apoio suficiente e também por não terem acesso do modo adequado e em tempo oportuno ao andamento das ações do programa e aos resultados das diversas avaliações. 0 PMAQ hoje "contamina" e informa muito menos do que poderia o cotidiano da gestão do processo de trabalho das equipes no território. Assim, como comentamos a importância dessa informação para os trabalhadores, poderíamos analisar também benefícios de uma comunicação/ participação ampliada dos demais atores como usuários organizados, cidadão e universidades, cuja mobilização e esforço à produção de conhecimentos e desenvolvimento de tecnologias para a qualificação dos sistemas locais de saúde parece ser uma aposta relevante no sentido de ampliar o papel das mesmas não só nos processos de avaliação e certificação do programa e sim na direção de um movimento que avance em termos de acesso e qualidade.

Para finalizar, vale destacar que, a despeito das críticas e apontamentos que apresentamos nesse ensaio, consideramos que o PMAQ é um programa oportuno, bastante exitoso e com um potencial de produção de mudanças ainda maior do que o que já pôde ser verificado. ${ }^{15,16}$

O objetivo do ensaio foi justamente chamar a atenção e fomentar o aprendizado com políticas que ousaram sairdo tradicional.
Que arriscaram desafiar o modus operandi regular da máquina de governo e inovaram em seus formatos porque apostaram que seria possível produzir mudanças na micropolítica do trabalho em saúde a partir de um processo disparado nacionalmente. Inovaram por apostar que uma política nacional molar $^{18}$ pode sim mobilizar transformações moleculares quando os diversos atores nos diversos níveis tomam parte no movimento.

Neste ensaio apostamos que analisar essas políticas, as teorias que Ihes informam, os formatos e modelagens que assumem, as dificuldades pelas quais passam, os desafios de sua formulação, operacionalização, gestão, monitoramento, avaliação e renovação, sem dúvida alguma, pode enriquecer muito a caixa de ferramentas do analista, do gestor e do militante. Fortalecendo a caixa de ferramentas, destaca uma capacidade relevante para a gestão da saúde, nem sempre visível no cotidiano: a capacidade de tomar decisões com informações capturadas no cotidiano do trabalho. A gestão assim constituída transborda a capacidade de uso de instrumentos e tecnologias e torna-se também exercício de pensamento vivo e criativo. $O$ gestor como operador de trabalho vivo e não apenas um ator constrangido por limites contextuais e por jogos de interesse. Não apenas um jogador, mas um pesquisador-inventor que também tem a capacidade da artesania criativa de produzir jogos que deixem a vida fluir e as saúdes aflorarem. Afinal, a saúde que compõe o escopo da Reforma Sanitária brasileira não é apenas relativa ao processo de adoecimento ou do bom funcionamento do sistema sanitário. Ela é a vida vivida como democracia radical, como expressão de diversidades e o combate às injustiças. Para essa ação setorial, as políticas necessitam de pedagogias voltadas para a inovação. Esse diálogo precisa seguir! 


\section{Referências}

${ }^{1}$ Menicucci, TMG. Implementação da Reforma Sanitária: a formação de uma política. Saúde e Sociedade, 2006 mai-ago; 15(2): 72-87.

${ }^{2}$ Menicucci, TMG; Brasil, FPD. Construção de agendas e inovações institucionais: análise comparativa da reforma sanitária e da reforma urbana. Estud. Sociol., 2010; 15(29): 369-396.

${ }^{3}$ Cortes, SMV. Atores, mecanismos e dinâmicas participativas. Em: Cortes, SMV (Orgs.). Participação e saúde no Brasil. Rio de Janeiro: Fiocruz; 2009: 19-39.

${ }^{4}$ Luz, MT. As instituições médicas no Brasil. Porto Alegre: Rede Unida; 2014.

${ }^{5}$ Brasil. Ministério da Saúde. Secretaria de Atenção à Saúde. Humaniza/SUS: documento base para gestores e trabalhadores do SUS. 4ed. Brasília: Ministério da Saúde; 2008.

${ }^{6}$ Brasil. Ministério da Saúde. Secretaria de Atenção à Saúde. Política Nacional de Humanização da Atenção e da Gestão no SUS. Brasília: Ministério da Saúde; 2009.

${ }^{7}$ Menezes, ELC. O que dá certo no SUS que dá certo? Histórias de inovação na produção da saúde na atenção básica presentes na Rede HumanizaSUS. Dissertação (Mestrado em Saúde Coletiva) - Universidade de Brasília, Brasíla; 2013.

${ }^{8}$ Brasil. Ministério da Saúde. Portaria 198, de 13 de fevereiro de 2004. Institui a Política Nacional de Educação Permanente em Saúde como estratégia do Sistema Único de Saúde para a formação e o desenvolvimento de trabalhadores para o setor e dá outras providências. Brasília; 2004.

${ }^{9}$ Ceccim, RB. Educação permanente em saúde: desafio ambicioso e necessário. Interface: comunicação, saúde, educação. set. 2004/fev. 2005. São Paulo; 9(16): 161-77.

${ }^{10}$ Ceccim, RB; Ferla, AA. A educação e saúde: ensino e cidadania como travessia de fronteiras. Trabalho, Educacão e Saúde, nov.2008/fev.2009; 6(3): 443-456.

${ }^{11}$ Ceccim, RB; Feuerwerker, LCM. O Quadrilátero da Formação para a Área da Saúde: Ensino, Gestão, Atenção e Controle Social. Physis: Rev. Saúde Coletiva, Rio de Janeiro; 2004; 14(1): 41- 65.

${ }^{12}$ Merhy, EE. Saúde: a cartografia do trabalho vivo. São Paulo: Hucitec; 2002.

${ }^{13}$ Lourau, R. Análise institucional. Petrópolis: Vozes; 1995.

${ }^{14}$ Pinto, HA; Sousa, A; Florêncio, AR. O programa nacional de melhoria do acesso e da qualidade da atenção básica: reflexões sobre o seu desenho e processo de implantação. RECIIS: Revista eletrônica de comunicação, informação e inovação em saúde. Ago., 2012. Rio de Janeiro; 6(2): Sup.

${ }^{15}$ Pinto, HA. Múltiplos olhares sobre e a partir do Programa Nacional de Melhoria do Acesso e Qualidade. Dissertação (Mestrado). Escola de Enfermagem, Programa de pós-graduação em Saúde Coletiva. Porto Alegre: UFRGS; 2014.

${ }^{16}$ Pinto, HA; Sousa, A; Ferla, AA. O Programa Nacional de Melhoria do Acesso e da Qualidade da Atenção Básica: várias faces de uma política inovadora. Saúde em Debate, Rio de Janeiro, 2014; Número especial sobre avaliação da atenção básica.

${ }^{17}$ Deleuze, G; Guatarri, F. Mil Platôs: Capitalismo e Esquizofrenia. 1v.. Rio de Janeiro: Editora 34; 1995.

${ }^{18}$ Guatarri, F. As três ecologias. Campinas: Papirus; 1990. 